\title{
Simulation and Visualization of Coupled Hydrodynamical, Chemical and Biological models*
}

\author{
DAG SLAGSTAD and TORLEIF IVERSEN†
}

Keywords: Modelling simulation, carbon cycle, hydrodynamics, plankton

This paper briefly describes the principles of hydrodynamical and ecological modelling of marine systems and how model results are presented by use of MATLAB. Two application examples are shown. One refers to modelling and simulation of the carbon vertical transport in the Greenland Sea and the other is a study on the effect of wind pattern for the invasion success of zooplankton from the Norwegian Sea into the North Sea by use of particle tracking.

\section{Introduction}

One of the first attempts to model fish populations for an optimal management of fish stocks was reported by Schaefer (1957). His work was refined by Beverton and Holt (1957). Only single species with no interaction with the environment were modelled. For management these models worked well under stable conditions, but e.g. changes in the climatic conditions leading to a perturbation in one fish stock would generally give serious effects in the others.

Ecological models including the interaction with their physical environment and other species started to develop in the sixties and seventies. Due to lack of computer capacity these models had a simple structure, often 1-dimensional (in the vertical direction) where the physical forcing was more or less specified (Slagstad 1985, Fasham 1990).

An ecological model in three spatial dimensions requires a hydrodynamical model which can produce time dependent fields of water flow, temperature, salinity and vertical mixing coefficients. These hydrodynamic models started to develop in the late seventies, but did not come into extensive use until the late eighties (Walsh et al. 1988. Slagstad and Støle-Hansen 1991).

The marine ecological system responds to seasonal changes in light flux, circulation pattern and in formation and melting of ice on one hand, and on the other (1) meteorological changes on a shorter time scale. Naturally, the seasonal dynamic's increases as we move away from equator. In addition, the dynamics tends to be more pronounced in the lower part of the biological hierarchy, i.e. for algae and zooplankton. Models of these organisms plus nutrients are used, not only to increase the understanding of them, but also to reproduce actual situations in response to seasonil or meteorological changes. For such simulations conclusions can be drawn upon the availability of food for the high level organisms like commercial fish species. Fish

Received 16 December 1996.

*An early version of this article wats presented at the SIMS '96 Applied Modelling and Simulation Conference, Trondheim, Norway, June 11-13 1996.

†SINTEF Electronics and Cybernetics, Automatic Control, N-7034 Trondheim, Norwaly, 
models, however, have not reached the same degree of confidence as these organisms have a more pronounced eigenbehaviour.

The ecological models are to some extent controlled by hydrodynamic phenomena on a relatively small scale (upwelling, patchiness, etc.). Such phenomena can be reproduced either by a finer spatial resolution, or by statistical modelling and repeated (Monte Carlo) runs. Thus, computer capacity is in many cases the limiting factor. In addition, some presentation techniques are quite demanding. There are virtually no limit to the computer resources that can be put into use, e.g. for animation of time dependent distributions.

\section{Hydrodynamical model}

\section{Basic equations}

The primary forces that cause motion of water are gravitation, both terrestrial and due to the sun and moon, wind stress and air pressure. A secondary force which comes into being when water starts to move is the Coriolis force, an apparent force compensating for the fact that the earth cannot be considered as an inertial system for ocean currents. The Coriolis force is significant for movements comparative to the rotating diameter. In addition, friction acts at the boundary of the fluid and tends to oppose its motion and smooth the motion within the fluid. The basic equations describing any fluid motion are the Navier-Stokes equations. They appear in various shapes dependent on the chosen coordinate system and the forces included.

Taking horizontal and vertical turbulent diffusion of momentum into consideration, the Navier-Stokes equations describing the movement of an incompressible fluid on a rotating base give the following equations for acceleration in the $\mathrm{x}$ - and $\mathrm{y}$-directions:

$$
\begin{aligned}
& \frac{\partial u}{\partial t}=f v-u \frac{\partial u}{\partial x}-v \frac{\partial u}{\partial y}-w \frac{\partial u}{\partial z}-\frac{1}{\rho} \frac{\partial p}{\partial x}+A_{\nu} \nabla^{2} u+\left(\frac{\partial}{\partial z} A_{v} \frac{\partial u}{\partial z}\right) \\
& \frac{\partial v}{\partial t}=-f u-u \frac{\partial v}{\partial x}-v \frac{\partial v}{\partial y}-w \frac{\partial v}{\partial z}-\frac{1}{\rho} \frac{\partial p}{\partial y}+A_{h} \nabla^{2} v+\left(\frac{\partial}{\partial z} A_{v} \frac{\partial v}{\partial z}\right)
\end{aligned}
$$

where $u$ and $v$ are the horizontal velocity components in the $x$ and $y$ direction, $f$ is the Coriolis parameter (depending of latitude), $\rho$ is the density, $A_{h}$ is the horizontal turbulent diffusion of momentum, $A_{v}$ is the vertical turbulent diffusion of momentum and $p$ is the pressure calculated from the hydrostatic equation:

$$
p(z)=\int_{z}^{n} \rho g d z+p_{\text {atm }}
$$

Here is $p_{\text {atm }}$ the atmospheric pressure. The vertical velocity $(w)$ is derived from the continuity equation for incompressible fluids:

$$
\frac{\partial w}{\partial z}+\frac{\partial u}{\partial x}+\frac{\partial v}{\partial y}=0
$$

and the surface elevation $(\eta)$ derives from:

$$
\eta=\int w_{1} d t
$$

where $w_{1}$ is the vertical velocity of the surface, $\eta$ is the height of the free surface relative to an undisturbed average value.

The variation of the density in space and time is calculated from an equation of state 


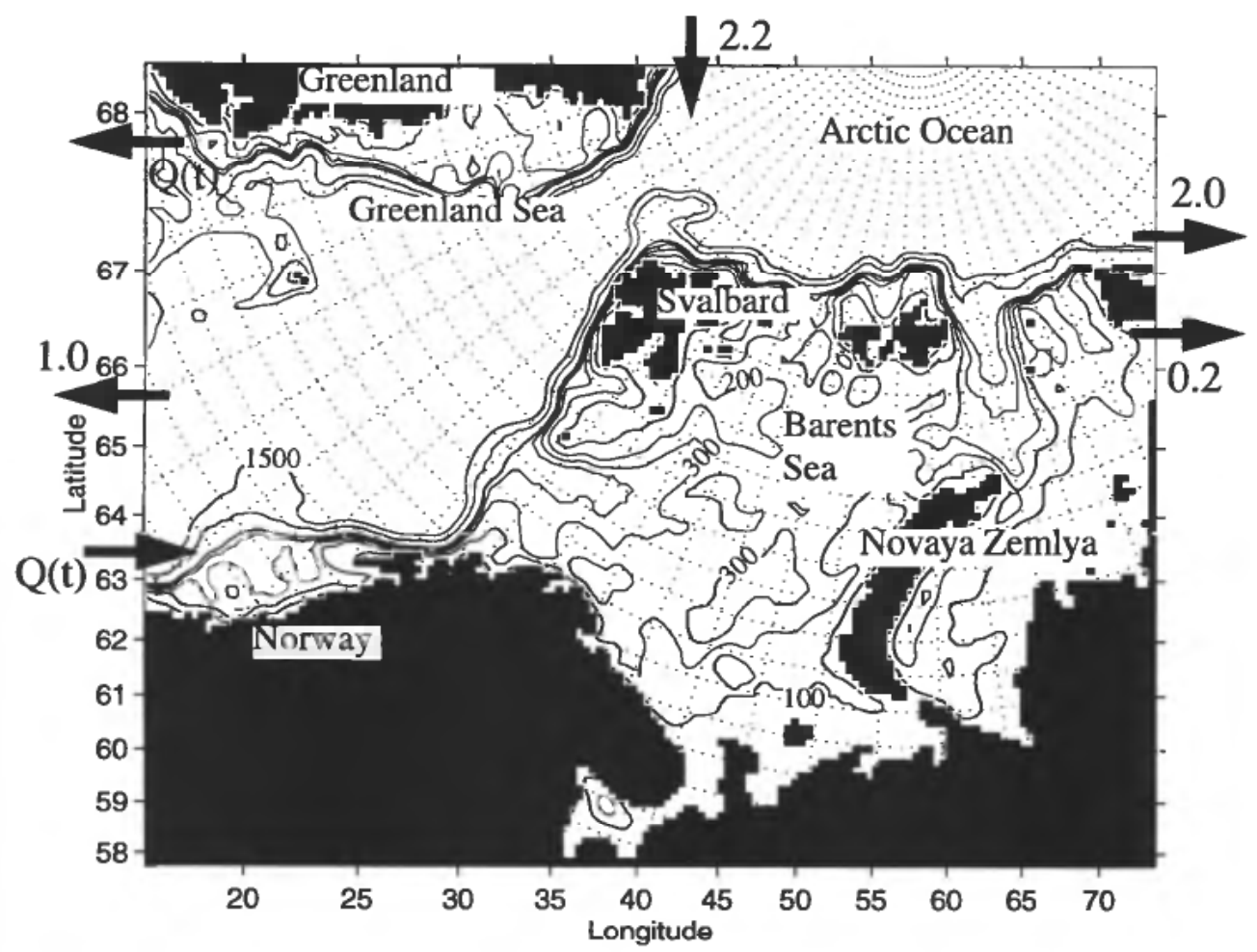

Figure 1. Model domain and specified fluxes through the boundaries in Sv.

$\rho=\rho(S, T)$ where $S$ and $T$ are salinity and temperature. These scalar fields can be modelled by the balance equation

$$
\frac{\partial c}{\partial t}=-\frac{\partial}{\partial x}(u c)-\frac{\partial}{\partial y}(v c)-\frac{\partial}{\partial z}(w c)+K_{h} \nabla^{2} c+\frac{\partial}{\partial z}\left(K_{v} \frac{\partial c}{\partial z}\right)+\delta_{c}
$$

where $c$ is either $S$ or $T, K_{h}$ is the horizontal turbulent diffusion of salinity and temperature, $K_{v}$ is the vertical turbulent diffusion of salinity and temperature and $\delta_{c}$ represents the flux of either heat or fresh water through the sea surface. $\nabla^{2} \equiv \partial^{2} / \partial x^{2}$ $+\partial^{2} / \partial y^{2}$ is the Laplace operator in two dimensions.

\section{Model configuration and driving forces}

The model area is shown in Figure 1. The depth of the levels from the surface is $10,5,5,5,5,5,5,10,25,25,25,25,25,25,50,100,200,400$ and $1,000 \mathrm{~m}$, i.e. 20 layers covering down to $2,000 \mathrm{~m}$ depth. The horizontal grid point distance is $20 \mathrm{~km}$. The number of horizontal grid points is $150 \times 120=18,000$.

The annual inflow of Atlantic water into the Norwegian, Icelandic and Greenland Sea based on heat budgets was calculated by Worthington (1970) to approximately $8 \mathrm{~Sv}^{1}$. Comparable estimates were presented by Mysak and Schott (1977) and Gould et al. (1985). The monthly average estimates can however vary between 4 and $12 \mathrm{~Sv}$ (Gould et al. 1995, McClimans 1993). In the simulation presented here the inflow of Atlantic water along the coast of mid Norway (Møre) varies according to McClimans (1993). The minimum in spring is $4 \mathrm{~Sv}$ and the maximum in December is $12 \mathrm{~Sv}$. The

${ }^{1} 1 \mathrm{~Sv}$ (Sverdrup) $=10^{6} \mathrm{~m}^{3} \mathrm{~s}^{-1}$ 
main outflow from the model area goes via the East-Greenland Current. The flux of water through the open boundaries of the model area is indicated in Fig. 1.

The initial density field is based on the Levitus world database for temperature and salinity. Wind and the atmospheric pressure were taken from the hindcast database of the Norwegian Institute of Meteorology (MI). These data are available on a $75 \mathrm{~km}$ grid and interpolation to the model grid was necessary. The area east of Novaya Zemlya is not covered by the MI database and the wind and air pressure fields thus had to be extrapolated. In order to calculate the heat flux, air temperature and humidity, cloud cover from meteorological stations within the model area was used. The coverage along the coast is relatively good. Unfortunately Russian data were not available. We have therefore postulated the climatic development on Franz Josef Land, Novaya Zemlya and on the Kola peninsula based on a climatological atlas and educated guesses and then interpolated the meteorological variables on a horizontal grid covering the model area.

The hydrodynamical model is a so-called box model which has velocities defined on the cell walls and scalars in the center of the cell. The advantage is an intuitive model with good conservation properties. The discretisation is explicit, which means that the time step is limited by stability. Equations (1)-(2) are hyperbolic and our discretisation roughly gives a maximum time step that is proportional to the ratio between the grid size and the flow velocities involved. Thus, halving the grid size in each horizontal dimension gives four times as many cells and approximately doubles the number of time steps - in total, an increase in the computational load by a factor of eight. For this reason a nesting technique has been included that enables a finer grid in certain regions of the model area.

\section{Chemical and Biological models \\ Carbon cycle}

In the recent years there has been a debate on the climatic effect of the increasing amount of $\mathrm{CO}_{2}$ in the atmosphere. $\mathrm{CO}_{2}$ has the property that it allows electromagnetic radiation with wave lengths in the visual range (i.e. radiation from the sun) to pass through whereas longer wave lengths (i.e. heat radiation from the Earth) is absorbed. About half of the antropogenic carbon ever released into the atmosphere still remains. The other half is partly absorbed by the oceans and terrestrial sinks. It is believed that most of this carbon is absorbed by the sea, but when the transport is quantified from the known processes, only half of the missing carbon can be accounted for. Two options are possible: the calculation can be wrong due to lack of understanding of the processes involved in the air-sea transport of carbon, or there exists a terrestrial sink which is not discovered or one which is just underestimated. In order to increase our understanding of the processes in a high latitude ecosystem an international EU-funded project (ESOP) has focused on the role of the Greenland Sea in the global carbon cycle. Here we will present some results from a project that is aimed to study the importance of biology in the carbon transport of the Greenland Sea.

There is about 50 times as much carbon in the ocean as in the atmosphere. Therefore, in a steady state situation, only $2 \%$ of the antropogenic carbon should be found in the atmosphere. The time constant for this process is, however, of the order of several hundred years. The reason is the vertical structure of the ocean which is dominated by a permanent density gradient some place between 100 and $500 \mathrm{~m}$ below the surface which inhibits vertical mixing. In order to put carbon down into this layer, one needs particles that are sinking or swimming.

$\mathrm{CO}_{2}$ as a gas is very stable. Dissolved in sea water it is highly reactive which 
involves complex reactions with other components. Three carbon species are formed: carbonate $\left(\mathrm{CO}_{3}^{-}\right)$, bicarbonate $\left(\mathrm{HCO}_{3}^{-}\right)$, and $\mathrm{CO}_{2}$. Most of the carbon is found as carbonate and bicarbonate and only $1 \%$ is in the form of $\mathrm{CO}_{2}$. The total dissolved inorganic carbon $\left(\mathrm{CO}_{3}^{-}+\mathrm{HCO}_{3}^{-}+\mathrm{CO}_{2}\right)$ is often expressed as $\Sigma \mathrm{CO}_{2}$. The air-sea flux of $\mathrm{CO}_{2}(F)$ is given by

$$
F=K_{A}\left(p C O_{2}^{\text {sea }}-p C O_{2}^{\text {atm }}\right)
$$

where $p \mathrm{CO}_{2}^{\text {sea }}$ is the partial pressure of $\mathrm{CO}_{2}$ in the sea, $p \mathrm{CO}_{2}^{\text {atm }}$ is the partial pressure of $\mathrm{CO}_{2}$ in the atmosphere and $\mathrm{K}_{A}$ is the air-sea transfer constant which is almost proportional to the wind speed. $p \mathrm{CO}_{2}^{\text {atm }}$ is nearly constant through the year (about $360 \mathrm{ppm}^{1}$ ), whereas $p \mathrm{CO}_{2}^{\text {sea }}$ increases with sea temperature.

The temperature effect on the $p \mathrm{CO}_{2}^{\text {sea }}$ is often called the "physical carbon pump" which gives outgassing of $\mathrm{CO}_{2}$ at low latitudes and absorption at high attitudes. When warm surface water flows north, it gradually cools and the $\mathrm{CO}_{2}$ pressure in the surface water decreases with the same amount of $\Sigma \mathrm{CO}_{2}$. Therefore, at high latitudes there is a net transport of $\mathrm{CO}_{2}$ from the atmosphere into the sea.

\section{Plankton}

Plankton is by definition plants and animals that depends on ocean currents for horizontal transport. A large fraction of the animal plankton, the zooplankton, is able to migrate vertically in the water column.

The counterparts to plants on land is the planktonic algae which has a size range from 1 to about $100 \mu \mathrm{m}$. As for land plants, the requirements for growth are light and nutrients supply. In the photosynthesis they extract $\mathrm{CO}_{2}$ from the water, use the carbon atom for building organic tissue and release the oxygen. The energy required for this process is provided by the light.

Energy transfer from algae to harvestable resources (fish) goes through the zooplankton. These organisms are animals in the size range from $100 \mu \mathrm{m}$ to $2-3 \mathrm{~cm}$. In the Greenland Sea the zooplankton community can be divided in two groups: micro-zooplankton (represented by the Oithona species) with a growth rate in the same order as the phytoplankton and a larger sized organism called Calanus hyperboreus which is a much slower growing animal with a generation time of two years. The biomass of Oithona is much less than Calanus since the mortality rate is higher. Often we find that Calanus is feeding on Oithona when the concentration of phytoplankton is scarce.

The carbon entering into the photosynthesis may take three directions: (1) to sedimentation of algal cells usually as a result of depleted nutrients or a high density of phytoplankton; (2) into the tissue of grazing zooplankton which releases some carbon as through respiration when the energy is needed or the animal dies; and (3) into faecal pellets because zooplankton does not assimilate all the material that is ingested and releases a fraction of undigested matter. These pellets may have a sinking rate in the order of 50 meter per day.

Calanus hyperboreus stays most of the year at depths below $1,000 \mathrm{~m}$ and ascends to the surface for feeding just in the productive summer months, May to July. In August most of the stock has left the surface layer. This means that the carbon will be

\footnotetext{
${ }^{1}$ ppm-parts per million.
} 


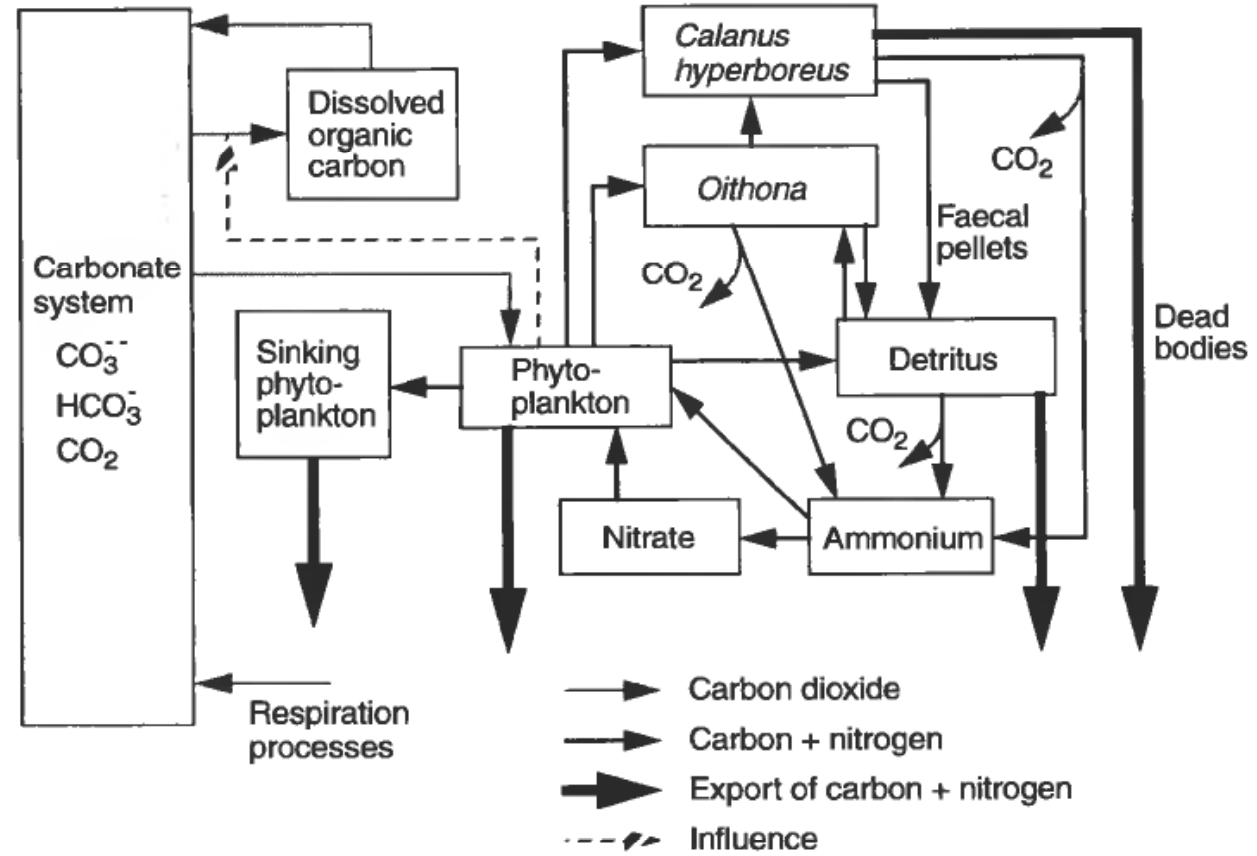

Figure 2. Conceptual biological and chemical models.

transported to the deep water by downward migrating animals. During the winter, a large fraction of this carbon will be released as $\mathrm{CO}_{2}$ through respiration.

The conceptual version of the biological model is shown in Fig. 2 where the flow of carbon and nitrogen between the different reservoirs is emphasized. For more details, see Slagstad et al. (in prep.).

\section{Particle tracking}

Simulating the spread of a constituent from a point source is usually done by so-called particle tracking or in a Lagrangian framework. Particles are released into the flow field and the spatial distribution can be calculated as a function of time. The advantage of this method compared to the more classical Eulerian advection is that horizontal numerical diffusion can be avoided.

The most important zooplankton species in the North Sea is Calanus finmarchicus. This species overwinters at depths below $600 \mathrm{~m}$ which is mainly found outside the shelf break in the Norwegian Sea (Fig. 3). Each spring the Calanus invades the Northern North Sea and serves as food for the larvae of several commercially exploitable fish stocks. The amount of Calanus that enters the North Sea seems to vary from year to year. The reason for this could be a variable size of the overwintering stock or variability in the transport from the Norwegian Sea to the North Sea. Variability in the inflow to the North Sea is mainly caused by the prevailing wind pattern. In order to investigate how the wind may affect the invasion to the North Sea, a hydrodynamical model was run with wind from different directions. Particles were released in areas where we know that Calanus is overwintering (Fig. 8A), i.e. where the depth is greater than $600 \mathrm{~m}$ in the areas Northeast of the Wyville-Thomson ridge. 


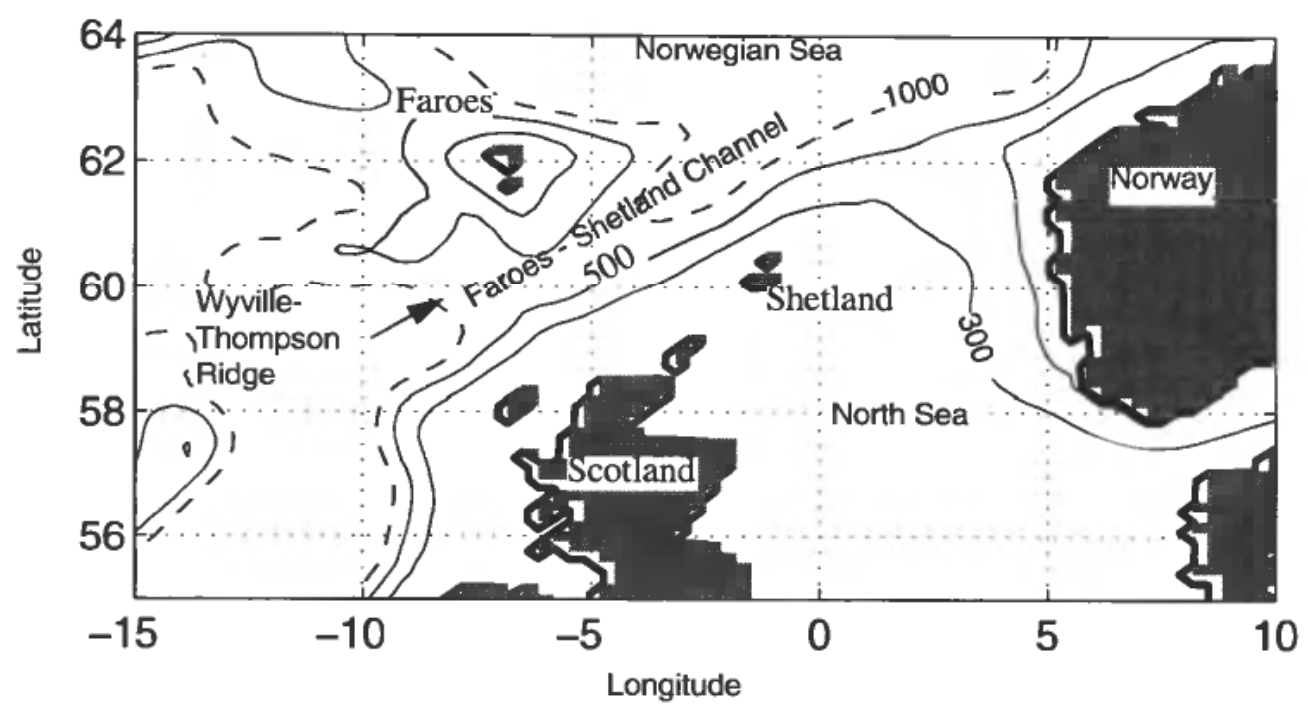

Figure 3. Study area of spring invasion of Calanus finmarchicus from the Norwegian Sea to the North Sea.

\section{Presentation tools}

\section{MATDISP}

Simulations using 3-dimensional hydrodynamical models produce a large amount of data which need to be analysed after each simulation run. One year of daily averaged flow fields for the arera shown in Fig. 1 takes $600 \mathrm{Mb}$. A typical simulation run with the chemical and biological variables produces about $200 \mathrm{Mb}$ of data. A menu driven presentation tool has been developed in MATLAB to present 3D model results. The simulation program always stores sufficient information allowing MATDISP to find the dimensions of the system, i.e. the number of grid points in the three physical dimensions, grid point distance, grid orientation relative to geographical coordinates, etc. Each stored field has a tag with a time stamp and an identification of the variable. MATDISP is able to present results both from the hydrodynamical and the biological models.

The capabilities of MATDISP are:

- Time series of any variable at any spatial position can be plotted

- Variables as function of the model coordinates or time can be selected

- The facilities in MATLAB to present 2D and 3D plots are used

MATDISP consists of several menu boxes assisting in the organization of a plot. Such menu boxes are:

- Axis-manipulates the axis (direction, colours, scaling, etc.)

- View-sets angle of view

- Movie-creates an animation of the simulation results

- Text-assists in placing the text on a plot

- Colors-interactive menu box for manipulating the colours of a plot

- Particle Tracking-interactive specification of particle release data 
remains low during the summer (Fig. 5C). Detritus which consists of dead organic matter increases during a short period in the early summer.

In early June there is a sudden drop in the primary production due to depletion of nitrate (Fig. 5A and E). This is a normal pattern which is found in the whole North Atlantic ocean. The production taking place after this event is either based on regenerated nutrients (excretion products from animals and bacteria) or transport of nutrients from the large pool below the pycnocline.

The drop in inorganic carbon follows a similar pattern as the nitrate (Fig. 5G), but starts to increase again earlier as a consequence of air-sea exchange of $\mathrm{CO}_{2}$. The surface $p \mathrm{CO}_{2}$ is down to less than $250 \mathrm{ppm}$ just after the spring bloom (Fig. $5 \mathrm{H}$ ). Since the air-sea exchange is proportional to the difference between $\mathrm{pCO}_{2}$ in sea water and $p \mathrm{CO}_{2}$ in the atmosphere, the input of $\mathrm{CO}_{2}$ to the sea is high during the summer months (Fig. 5I). Towards the winter the transport into the sea decreases again due to the small difference between $p \mathrm{CO}_{2}^{\text {sea }}$ and $p \mathrm{CO}_{2}^{\text {atm }}$, although the wind speed usually increases in this region at that time.

One necessary condition for the start of an algal bloom is that the vertical mixing cannot be too deep in relation to the available light (Sverdrup 1953). Along the Norwegian coast this is achieved through fresh water run-off from land and in Polar regions by melting ice. ${ }^{1}$ Thus, at the end of May we have a low concentration of $p \mathrm{CO}_{2}^{\text {sea }}$ ( 280 to $300 \mathrm{ppm}$ ) near the coast of Norway (Fig. 6, upper right panel). At the ice border $p \mathrm{CO}_{2}^{\text {sea }}$ has dropped below $200 \mathrm{ppm}$. This is due to the difference in temperature we find between the two regions.

Along the Norwegian coast, the temperature increases rapidly which decreases the solubility of $\mathrm{CO}_{2}$ whereas the temperature remains close to the freezing point near the ice border. Later in spring or summer the $p \mathrm{CO}_{2}^{\text {sea }}$ decreases in the oceanic regions as a result of biological activity.

In the Greenland Sea the annual primary production during the simulation was $68 \mathrm{~g} \mathrm{Cm}^{-2}$, of which $50 \mathrm{~g} \mathrm{C} \mathrm{m}^{-2}$ was new production. ${ }^{2}$ Export through a surface placed at $75 \mathrm{~m}$ was $27 \mathrm{~g} \mathrm{Cm}^{-2}$ and the total flux of carbon from the atmosphere to the sea was $50 \mathrm{~g} \mathrm{Cm}^{-2}$. The area distribution of the air-sea carbon flux is shown in Fig. 7. Along the Norwegian Coast the carbon flux is low and even negative in the southern end of the model domain. Further offshore and to the North the annual flux increases as a consequence of decreasing temperatures and biological activity. The highest flux is found along the ice border in the Greenland Sea where up to $70 \mathrm{~g} \mathrm{Cm}^{-2}$ is absorbed per year.

\section{Particle tracking}

A hydrodynamical model, similar to the one described above was implemented for the North Sea and Norwegian Sea with a horizontal grid resolution of $20 \mathrm{~km}$. Wind from different directions was applied to simulate flow field scenarios used to investigate the effect of wind in the invasion of Calanus finmarchicus to the North Sea.

\footnotetext{
${ }^{1}$ When ice is formed, salt is released. Melting will thus create surface layer of low salinity water.

${ }^{2}$ New production is based on nitrate and is regarded as the potentially harvestable production from the system. Such harvest is usually taken out as fish on top of the biological levels, but in The Greenland Sea the fish is of no importance. The rest of the production is based on regenerated nutrients.
} 

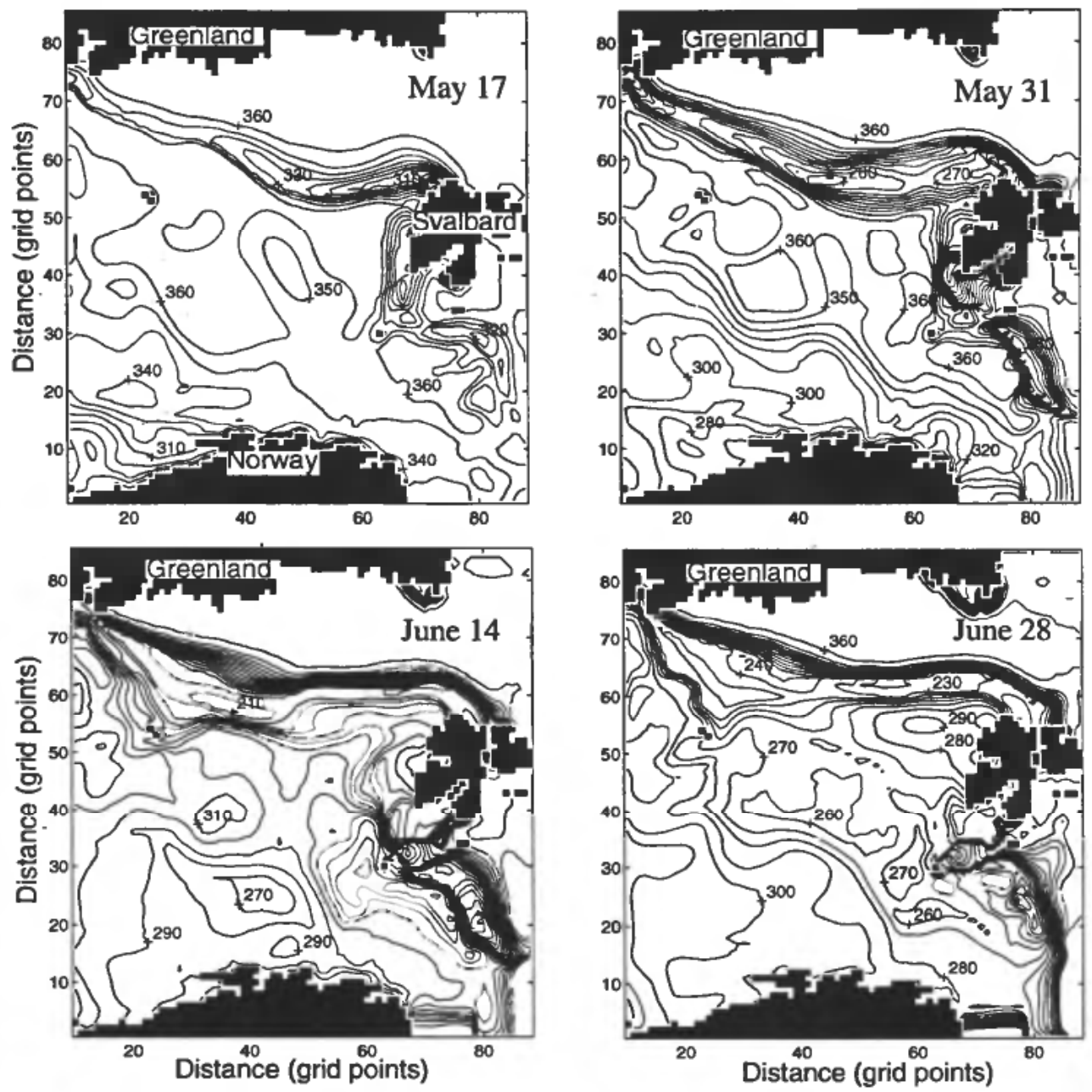

Figure 6. Simulated $p_{\mathrm{CO}_{2}}$ at selected dates as a result of combined effect warming and biological production. Initial values were put equal to $360 \mathrm{ppm}$ in late winter.

Particles simulating vertical migrating behaviour of $C$. finmarchicus were released from a $500 \mathrm{~m}$ surface in the Norwegian Sea (Fig. 8A). During one month they migrated towards the surface and stayed there. A particle was released from each release site every 12 hours during a 20 day period. Random noise having a rectangular distribution with a maximum value of $250 \mathrm{~m}$ were added to the position at each time step ( 1 hour). The target area investigated is indicated by a dashed, rectangular box.

The origin probability (i.e. the probability that a particle from a specific release site will reach the target area during the simulation period) shows that particles from a position $60^{\circ} \mathrm{N}$ and between 4 and $6^{\circ} \mathrm{W}$ have the highest probability of entering the target area. A few other spots along the southern Faroe shelf slope also contribute. The mean age of arrival (i.e. time in days from when the particle was released) was 55 days (Fig. $8 \mathrm{~F})$. There is a peak around day 40 which represents the arrival of particles released at the southern slope of the Faroe-Shetland Channel. Those released on the northern 


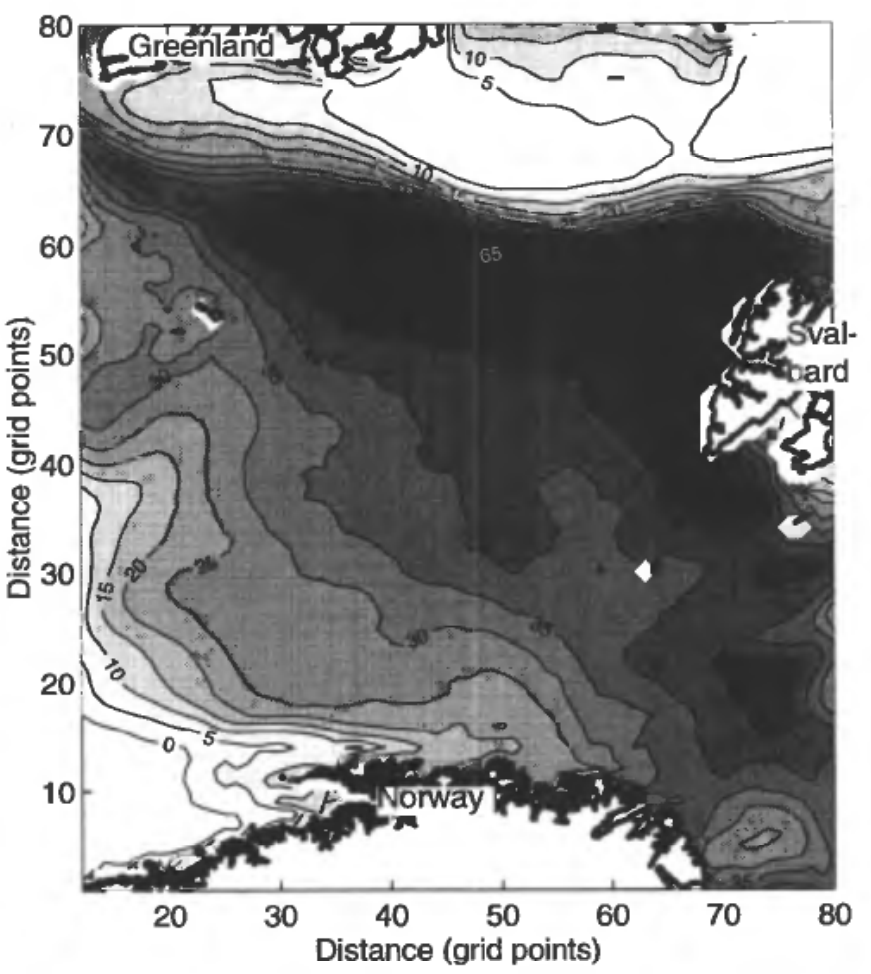

Figure 7. Integrated flux of carbon from the atmosphere to the sea.

side follow the currents along the slope in an anti-clockwise direction and need more time to enter the target box. Particles released in the middle of the channel follows a current regime which does not transport animals into the North Sea. The mean residence time in the box is only $\mathbf{1 5}$ days indicating a relatively strong flow regime in that area (Fig. 8B). The first particles arrived after drifting for 35-40 days (Fig. 8E). Maximum concentration (the number of particles in the box) occurred on day 60 (Fig. 8G).

Three different wind Scenarios were examined. (1) Wind from southwest (shown in Fig. 8), (2) average wind field for late winter in the area and (3) wind from northeast. The arrival successes to the chosen target box were 827,400 and 40 , respectively.

\section{Conclusions}

From a primitive equation model of ocean circulation, a literature based model of biology and carbon chemistry we have calculated the annual flux of carbon from the atmosphere to the sea in the Greenland sea area. Data for sea surface temperature and ice distribution are available from satellite measurements and show good agreement with the simulations. This is also the case for the primary production, but the data are much more scattered depending on cruises to the area (Noji et al. in prep., Sandvik et $a l$. in prep.). Simulated new production was $50 \mathrm{~g} \mathrm{Cm}^{-2}$ which is close to the estimate of Noji et al. (in prep.) based on nitrate utilization measured in the early autumn. The average flux of carbon is about $50 \mathrm{~g} \mathrm{C} \mathrm{m}^{-2}$ per year, but depends on the geographical location. In north, along the ice border, the drawdown of carbon has a maximum of $70 \mathrm{~g} \mathrm{C} \mathrm{m}^{-2}$ per year, whereas the corresponding value for the southern end of the Greenland Sea is $35 \mathrm{~g} \mathrm{Cm}^{-2}$. The Greenland Sea has an area of about $300000 \mathrm{~km}^{2}$, 

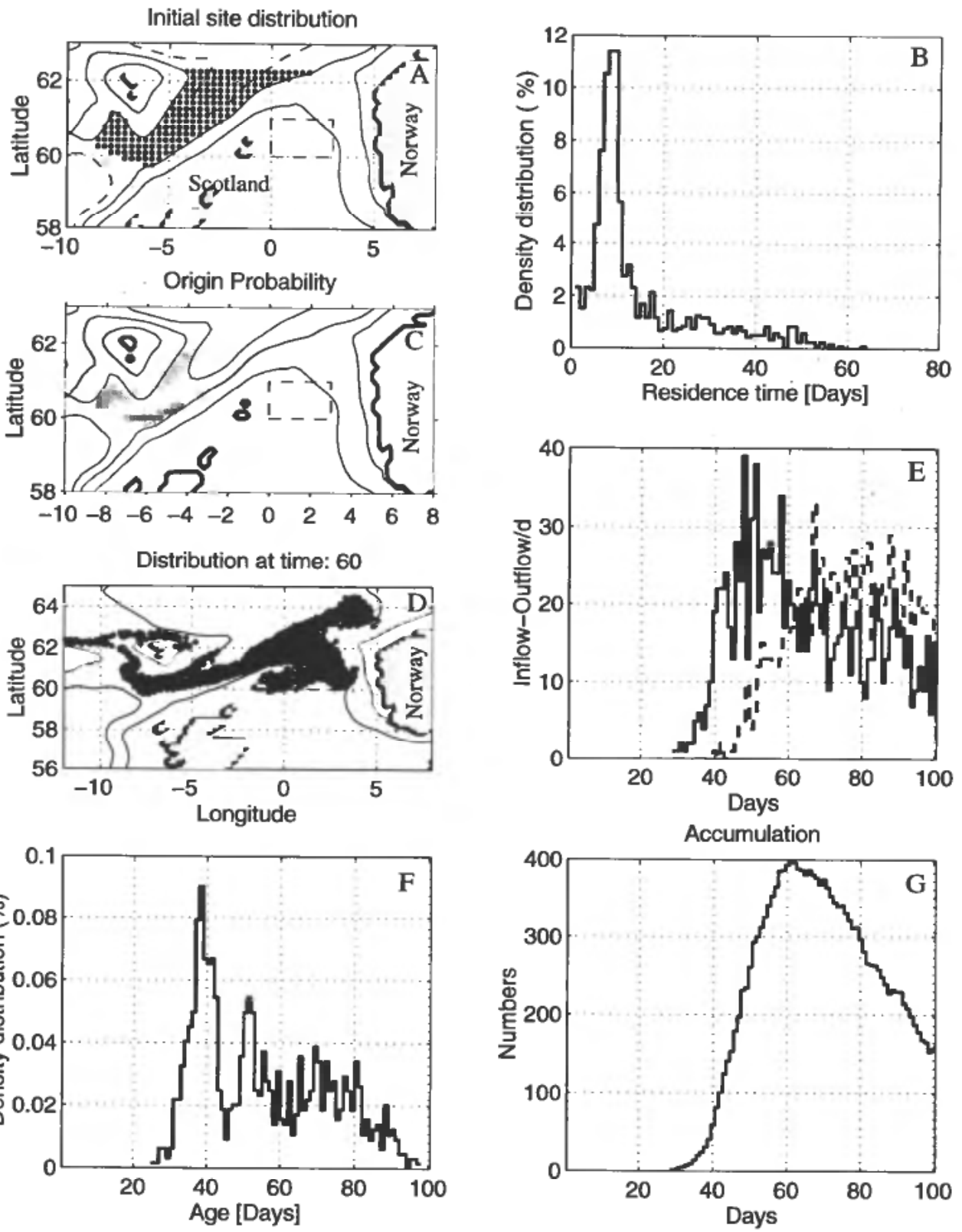

Figure 8. Results from a particle tracking experiment with northwesterly wind. (A) Release sites, the dashed box shows the position of the target box, (B) Density distribution of residence time, (C) origin probability, (D) distribution after 70 days, (E) Inflow (solid line) and outflow (dashed line) in number of particles per day, $(\mathrm{F})$ age of arrival at the target box and (B) number of particles in the target box as a function of time.

which means that this sea is capable of absorbing $0.015 \mathrm{Gt}$ of carbon per year. Johannessen et al. (in prep.) calculated the absorbtion for the Nordic Seas (Greenland, Iceland and Norwegian Seas) from measurements to be between 0.03 and $0.06 \mathrm{Gt}$ depending on the air-sea formula used. $0.015 \mathrm{Gt}$ for the Greenland Sea alone is therefore reasonable. 
Simulation of Calanus invasion to the North Sea clearly shows that southwest wind is the most effective wind direction and north east almost shut off the transport.

\section{ACKNOWLEDGEMENT}

This work was supported by the Research Council of Norway and European Commission projects ESOP (MAS2-DT93-0057) and ICOS (MAS2-CT94-0085.)

\section{REFERENCES}

BeVERTON, R. J. H. and Holt, S. J. (1957). On the dynamics of exploited fish populations. Fishery Invest. London. 2(10): 533 pp.

Fasham, M. J. R., Ducklow, H. W. and MCKelvie, S. M. (1990). A nitrogen based model of plankton dynamics in the oceanic mixed layer. J. Mar. Res., 48, 591-639.

Gould, W. J., LOYNES, J. and BACKHAUS, J. (1985). Seasonality in slope current transport NW of Shetland. ICES Paper C.M. 1985/C:7.

Johannessen, T., SkJelvan, I., Miller, K., Stoll, M. and Jansen, E. (in prep.). Carbon budget from surface $\triangle \mathrm{pCO}_{2}$.

MCClimans, T. A. (1993). An algorithm for computing monthly averaged inflow of Atlantic water to the Norwegian Sea. SINTEF Report, STF60 A93009.

MYSAK, L. and SCHOTT, F. (1977). Evidence for baroclinic instability of the Norwegian Current. J. Geophys. Res. 82, 2087-2095.

NoJi, T. T., ReY, F., MilleR, L., BøRSheIm, K. Y. and HiRCHe, H.-J. (in prep.). Seasonal patterns of plankton production and sedimentation in the Greenland Sea.

SANDVIK, R., DALløKKEN, R. and SAKSHAUG, E. (in prep.). Bio-optical studies in the Greenland Sea.

SCHAEFER, M. B. (1957). Some considerations of population dynamics and economics in relation to the management of marine fishes. Journal of the Fisheries Research Board of Canada, 14, 669-681.

Slagstad, D. (1985). A model of phytoplankton in the Marginal Sea-ice zone of the Barents Sea. In Gray \& Christiansen: Marine Biology of Polar Regions and Effects of Stress on Marine Organisms. John Wiley \& Sons Ltd.

Slagstad, D. and Støle-Hansen, K. (1991). Dynamics of plankton growth in the Barents Sea. Model studies. Polar Res. 10, 173-186.

Slagstad, D., Downing, K., CARLOTTI, F. and HirCHe, H.-J. (in prep.). A 3D model of the carbon cycle in the Greenland Sea.

Støle-Hansen, K. and Slagstad, D. (1991). Simulation of currents, ice-melting and vertical mixing in the Barents Sea using a 3-D baroclinic model. Polar Res. 10, 33-44.

Støle-Hansen, K., Slagstad, D. and Utnes, T. (1989). Baroclinic Model Test Case Information. SINTEF report STF48 F89002. Trondheim.

Walsh, J. J., Diterle, D. A., Meyers, M. B. (1988). A simulation analysis of the fate of phytoplankton within the Mid-Atlantic Bight. Cont. Shelf Res. 8, 757-787.

Worthington, L. V. (1970). The Norwegian Sea as a mediterranean sea. Deep-Sea Res. 17, $77-84$. 